\title{
Équipements sportifs innovants et développement d'une culture technique. L'exemple de la navigation sur des voiliers « volants "
}

Innovative sport equipment and development of a technical culture. The example of navigation on "flying" sailboats

Éric Terrien, Benoît Huet et Jacques Saury

\section{(2)enEdition Journals}

Édition électronique

URL : https://journals.openedition.org/activites/5762

DOI : 10.4000/activites.5762

ISSN : $1765-2723$

Éditeur

ARPACT - Association Recherches et Pratiques sur les ACTivités

\section{Référence électronique}

Éric Terrien, Benoît Huet et Jacques Saury, «Équipements sportifs innovants et développement d'une culture technique. L'exemple de la navigation sur des voiliers « volants » », Activités [En ligne], 17-2 I 2020, mis en ligne le 15 octobre 2020, consulté le 25 août 2021. URL : http://journals.openedition.org/ activites/5762; DOI : https://doi.org/10.4000/activites.5762

Ce document a été généré automatiquement le 25 août 2021.

\section{c) (†)}

Activités est mis à disposition selon les termes de la licence Creative Commons Attribution - Pas d'Utilisation Commerciale - Pas de Modification 4.0 International. 


\section{Équipements sportifs innovants et développement d'une culture technique. L'exemple de la navigation sur des voiliers « volants »}

Innovative sport equipment and development of a technical culture. The example of navigation on "flying" sailboats

Éric Terrien, Benoît Huet et Jacques Saury

\section{NOTE DE L'ÉDITEUR}

Article soumis le 18 décembre 2019, accepté le 15 mai 2020

\section{Introduction}

1 Dans la plupart des disciplines sportives, les athlètes interagissent avec leur environnement par l'intermédiaire d'équipements sportifs, qui peuvent être de natures diverses. Il peut s'agir d'équipements vestimentaires, d'accessoires réglementaires et de sécurité, d'instruments d'aide à la performance, etc. Ceux-ci peuvent également être des équipements mécaniques permettant des modes spécifiques de locomotion terrestre, nautique ou aérien - dont le pilotage est au cœur des techniques sportives des athlètes. Dans ce cas, les performances des athlètes dépendent de façon cruciale de la qualité de leurs interactions avec leur équipement, dans un environnement dynamique et incertain. De ce fait, les inventions et innovations technologiques ${ }^{1}$ qui marquent l'histoire de ces disciplines sont susceptibles d'engendrer à leur tour des évolutions techniques inédites, pouvant dans certains cas révolutionner la pratique 
d'un sport, et remettre en cause les techniques usuelles de la communauté sportive considérée.

2 Terret, Robène et Grosjean (2017) ont par exemple montré que l'invention de nouvelles figures en canoë-kayak dans la discipline « freestyle » est liée à l'apparition de bateaux plus courts, à fond plat et à carres. Ces bateaux ont ouvert ces nouvelles possibilités techniques pour les pagayeurs grâce à la vitesse, la maniabilité et la stabilité inédites que leur conféraient leurs formes de coque. Ces auteurs ont également pointé que ces innovations ont aussi été perçues comme hétérodoxes au regard de la tradition des disciplines dites «classiques» du canoë-kayak (ex. descente, slalom). De nombreux moniteurs et entraîneurs considéraient en effet que ces nouvelles formes de bateaux pouvaient constituer un obstacle à l'apprentissage de l'eau-vive en donnant aux élèves « de mauvaises habitudes de navigation » (Terret et al., 2017, p. 60).

Dans le domaine de la voile sportive, Bethwaite (2012) décrit la manière dont l'apparition de nouveaux voiliers au XIX siècle en Nouvelle Zélande, les Patikis, a conduit un groupe de navigateurs à développer de nouvelles techniques de navigation. Ces bateaux équipés d'une grande surface de voilure et d'une carène plate étaient particulièrement rapides, et ne pouvaient être contrôlés sans chavirer en mobilisant la technique de navigation enseignée à cette époque. Celle-ci consistait à maintenir la voile dans une position fixe par rapport au vent moyen et à la direction moyenne, et à contrôler le bateau uniquement à la barre en le dirigeant vers le lit du vent pendant les risées. Confronté à de nouvelles difficultés liées aux caractéristiques des Patikis, un groupe de navigateurs a développé ce que Bethwaite appelle la «fast handling technique ", qui consiste à utiliser conjointement la barre et l'écoute de voile ${ }^{2}$ pour contrôler vitesse et stabilité du bateau en exploitant les rafales de vent plutôt qu'en les subissant. Le développement d'équipements tels que les dériveurs vers le milieu du Xx $x^{e}$ siècle, puis la planche à voile dans les années 1970, a également fait émerger de nouvelles techniques de navigation dans lesquelles les actions des navigateurs ne se réduisaient plus à "conduire " un navire à l'aide des "commandes » classiques des voiliers (la barre, les écoutes de voile). Sur ces supports légers et instables, les corps des navigateurs devaient désormais s'intégrer au fonctionnement mécanique du bateau, suscitant l'apparition de techniques inédites, telles que les techniques du rappel et du trapèze, qui permettent au navigateur d'équilibrer l'embarcation en déportant son corps à l'extérieur du bateau. En planche à voile, le corps du véliplanchiste est encore davantage incorporé à son équipement. Il assure lui-même en partie la liaison mécanique entre le gréement et le flotteur, de sorte que le contrôle de la direction, de la propulsion et de l'équilibre de la planche reposent sur les ajustements corporels constants du véliplanchiste (Dant \& Wheaton, 2007).

4 Au-delà des cas particuliers du canoë-kayak et de la voile, l'histoire des techniques sportives regorge d'exemples mettant en évidence une relation étroite entre des inventions technologiques ou l'apparition d'équipements nouveaux, et l'invention corrélative de techniques corporelles inédites, puis leur formalisation et leur transmission à différents moments de l'évolution de chaque sport (Defrance, 1985 ; Vigarello, 1988). Plus généralement, les relations, entre le développement de technologies ou objets techniques inventés par les hommes, l'invention de nouvelles techniques sportives, et leur diffusion en tant qu'innovations, ont été largement montrées par les anthropologues des techniques (ex. Leroi-Gourhan, 1964). Dans les recherches sur le sport, ces relations ont été étudiées sur la base d'analyses 
rétrospectives de ces évolutions (ex. Defrance, 1985; Terret et al., 2017 ; Vigarello, 1988). En revanche, les possibilités d'analyser ces relations en train de s'établir, et dans une perspective d'analyse de l'activité des acteurs en cours d'invention, sont exceptionnelles. D'une part, les innovations technologiques pouvant être considérées comme majeures sont rares dans une discipline sportive. D'autre part, il est malaisé de présumer par anticipation l'impact de la diffusion de nouveaux équipements sur les techniques individuelles, et sur la culture technique ${ }^{3}$ du groupe d'acteurs concernés par cette innovation.

5 Le domaine de la voile sportive offre actuellement une opportunité particulièrement intéressante pour conduire une telle étude. Celle-ci est liée à la révolution que connaît actuellement l'ensemble des spécialités de voile, avec l'adjonction d'hydrofoils sur tous les types de voiliers, et la diffusion rapide actuelle des « voiliers volants » dans toutes les sphères de la pratique, depuis la voile de loisir jusqu'à la voile de haute compétition (Havard, Seray, \& Verneuil, 2018). Les hydrofoils (communément appelés foils) sont des ailes sous-marines, ou plans porteurs immergés, produisant une force de portance hydrodynamique. Lorsque la composante verticale de la portance des foils est suffisante pour compenser le poids du voilier et de son équipage, celui-ci s'extrait de la surface de l'eau et se met à « voler ».

6 Les premiers bateaux équipés de foils sont apparus dès le début $\mathrm{du} \mathrm{xx}^{\mathrm{e}}$ siècle. Ils se sont développés dans les domaines de la navigation militaire et commerciale (Clark, Ellsworth, \& Meyer, 2004). Cependant, jusqu'au début des années 2010, les foils ne se diffusent que de façon marginale dans le domaine de la voile sportive, faisant l'objet d'expérimentations pionnières isolées sur différents types de voiliers (Février, \& Monsonnec, 2011). Ce n'est que récemment, à la faveur des progrès réalisés dans la conception et la fabrication en grande série des foils en matériaux composites, que leur diffusion s'est accélérée dans le milieu de la voile. Introduits sur la Coupe de l'America en 2013, les voiliers à foils se généralisent actuellement dans le domaine de la course au large (ex. Vendée-Globe Challenge, Route du rhum, Solitaire du Figaro). Ils seront également représentés pour la première fois aux Jeux Olympiques de Tokyo en 2021, dans la série olympique Nacra 17 (catamaran à deux coéquipiers), et quatre séries olympiques à foil sont d'ores et déjà inscrites au programme des Jeux de Paris 2024 (sur dix au total). Les voiliers volants connaissent parallèlement un développement industriel et commercial important dans le domaine de la voile de plaisance et de loisir, notamment avec la diffusion du kitefoil (planche de kitesurf équipée d'un foil) et du windfoil (planche à voile équipée d'un foil).

7 Cette généralisation des foils sur les voiliers constitue manifestement une rupture et un changement de "paradigme technologique» (Dosi, 1982) dans le domaine de la voile sportive. Elle renvoie à ce que Freeman et Perez (1988) nomment une innovation radicale (ou révolution technologique), créant une discontinuité majeure par rapport au cadre technique déjà défini, par opposition à une innovation incrémentale (opportunité nouvelle plus discrète dans un cadre technique déjà défini) (pour une synthèse, voir Flichy, 2003). En l'occurrence, la navigation sur les voiliers à foils impose aux pratiquants une adaptation à des problèmes techniques inédits liés à l'extrême précarité de la stabilité du vol, à la brutalité des changements de régime de navigation, à la perte des repères usuels de trajectoire relative au vent associée aux très grandes vitesses de navigation (les voiliers se déplacent couramment à des vitesses supérieures 
au vent), ou encore à l'accès à des réglages inconnus sur les autres voiliers (ex. réglage de l'incidence des foils).

Ainsi, à l'instar du processus décrit par Defrance (1985), cette période de "révolution technologique » se traduit pour une partie des pratiquants - le plus souvent des experts du domaine - par une activité inventive de redéfinition d'un nouveau corpus de gestes sportifs. Celle-ci vise à découvrir grâce à une pratique exploratoire intensive les solutions techniques permettant d'optimiser leur interaction avec leur équipement matériel. Ainsi, les pratiquants et entraîneurs pionniers dans l'apprentissage et la recherche de performances sur ces nouveaux voiliers volants construisent des connaissances pratiques fortement indexées à des contextes particuliers, qui constituent en germe les éléments du développement d'une culture technique concernant la performance sur les voiliers volants. En effet, ces connaissances font l'objet de récits spontanés, et sont partagées de façon essentiellement informelle au sein d'une communauté de pratiquants spécialistes. Des premières tentatives de formalisation des connaissances et de partage d'expériences s'opèrent, notamment sous l'égide de la Fédération Française de Voile, et de l'École Nationale de Voile et des Sports Nautiques (ex. Flageul, 2018). De même, un nombre croissant d'articles de revues spécialisées (ex. Voiles et Voiliers, Voile Magazine, Sail Magazine) concernent spécifiquement la navigation sur voiliers volants. Ces initiatives accréditent l'idée d'un développement en train de se faire d'une culture technique propre à la navigation sur les voiliers à foils.

9 La présente étude visait à éclairer deux phénomènes essentiels. Le premier concernait la nature et la structure des connaissances que des pratiquants et praticiens pionniers de la navigation sur voiliers à foils ont développées pour résoudre un problème technique inédit dans la navigation sur foil en comparaison de la navigation dite « archimédienne » (i.e., voilier se déplaçant à la surface de l'eau) : le contrôle et le maintien d'une stabilité de vol. Le deuxième concernait le caractère plus ou moins partagé de ces connaissances, pouvant faire apparaître les éléments d'une culture technique en train de se construire.

10 Le choix de focaliser notre analyse sur les connaissances relatives aux conditions de contrôle et de maintien d'une stabilité de vol tient à ce que cette question apparaît comme la plus importante dans le domaine de la voile volante en termes d'adaptation technique. En effet, l'une des conditions cruciales de l'optimisation de la performance sur les voiliers volants est la capacité de l'équipage à maintenir le voilier en vol le plus longtemps possible, car les potentiels de vitesse des voiliers sont sans commune mesure lorsqu'ils sont en vol ou en navigation dite archimédienne, en raison de la diminution spectaculaire des résistances hydrodynamiques en phase de vol. C'est d'ailleurs principalement à cette capacité à maintenir leur catamaran à foil en vol durant l'intégralité de parcours de régate qu'a été imputée la victoire de l'équipage néozélandais sur l'équipage américain lors de la finale de la Coupe de l'America de 2017 (Destuynder \& Fabre, 2018). À ce titre, le maintien et le contrôle de la stabilité de vol constituent l'objectif prioritaire de tout équipage sur voilier à foil.

\section{Cadre théorique}

11 Les notions de connaissance et de culture technique ont été construites en accord avec une approche enactive de la cognition humaine (Varela, 1989), et plus particulièrement 
en référence au programme scientifique et technologique du Cours d'action (Theureau, 2006).

12 L'approche enactive de la cognition humaine considère celle-ci comme une propriété émergente du couplage structurel asymétrique d'un acteur avec son environnement (Varela, 1989). Ce couplage est asymétrique du fait de l'autonomie fondamentale de l'acteur, dont l'activité (en relation avec des prédispositions biologiques, perceptivomotrices, émotionnelles, culturelles), fait émerger (" enacte ») le monde avec lequel il interagit à chaque instant. Ce couplage structurel asymétrique et son caractère historique produisent un monde propre pour l'acteur, porteur de sens au travers des régularités, ou éléments de généralité, que celui-ci construit et reconnaît au gré de l'histoire des interactions acteur/environnement. De ce point de vue, la connaissance ne peut être conçue comme déterminée seulement par les caractéristiques du monde objectif, que l'acteur saisirait et qui guideraient son activité. Elle est fondamentalement liée au monde propre de chaque acteur. Pour autant, les connaissances construites par un acteur - en tant que régularités dans son expérience - ne sont pas radicalement singulières. En effet celles-ci rendent possible la coordination de différents acteurs et émergent également à l'occasion des interactions et échanges langagiers avec d'autres acteurs. Ces interactions entre acteurs correspondent à un couplage structurel de troisième ordre (ou encore couplage social) (Maturana \& Varela, 1987), duquel émergent les éléments d'un domaine consensuel au sein d'un groupe ou d'une communauté particulière.

13 En accord avec les présupposés de l'enaction, le programme de recherche du Cours d'action postule que l'activité d'un acteur s'accompagne d'un processus permanent d'apprentissage-développement situé et incarné, le conduisant progressivement à construire des éléments de généralité - ou connaissances - selon un principe de typicité (Rosch, 1978; Theureau, 2006). Autrement dit, l'acteur valide ou invalide à chaque instant des connaissances usuelles construites dans le cours de son expérience passée, et/ou construit de nouvelles connaissances, sur la base d'un gradient de similarité ou de ressemblance entre les expériences vécues (Theureau, 2006). Ces connaissances constituent les éléments du référentiel de l'acteur. Cette notion désigne la culture propre de l'acteur (Theureau, 2015), c'est-à-dire l'ensemble des connaissances construites ou renforcées dans le passé, et potentiellement mobilisables par cet acteur en relation avec son engagement dans chaque situation ou famille de situations particulières. Une part des éléments de cette culture propre peut être partagée par différents acteurs confrontés à une même famille de situations pratiques. Ce partage peut donner lieu à des étiquetages symboliques et langagiers et à des formalisations diverses concernant le domaine technique considéré. Dans ce cas, émerge un domaine consensuel (Maturana \& Varela, 1987), c'est-à-dire, un système symbolique culturel partagé par le groupe concerné (Theureau, 2015). Ainsi, une approche enactive de la culture articule la notion de culture propre d'un acteur, c'est-àdire la culture incorporée et située, émergeant du couplage structurel entre l'acteur et son environnement, avec une notion de culture comme système symbolique plus ou moins formalisé et réifié (se concrétisant dans des discours, textes, etc.).

14 Pour les besoins de la présente étude, deux catégories de connaissances ont guidé notre analyse des connaissances et de la culture partagée par les acteurs à propos du contrôle et de la conservation de la stabilité de vol sur les voiliers à foils. Celles-ci font référence 
aux notions de types et de relations entre types qui composent le référentiel de l'acteur (Theureau, 2006) :

- les expériences-types : la reconnaissance d'une expérience comme typique du point de vue du contrôle ou du maintien de la stabilité de vol, par analogie / différence avec des expériences passées. Ces expériences-types conduisent a priori les acteurs à délimiter, nommer, spécifier, différencier, des actions, perceptions, caractéristiques des situations, qui constituent leur monde propre lorsqu'ils évoquent et explicitent des moments significatifs pour eux de contrôle et de conservation de la stabilité de vol des voiliers ;

- les principes d'interprétation: l'établissement de relations entre différentes expériencestypes dans le cadre de chaînes interprétatives (ou causales) mobilisées par l'acteur pour expliquer/interpréter ces relations. Ces principes d'interprétation reflètent une forme de compréhension plus abstraite et générale par les acteurs des conditions de contrôle et de la conservation d'une stabilité de vol, leur permettant d'assimiler les diverses expériencestypes de vol, et de les inscrire dans un cadre interprétatif présentant une cohérence de leur point de vue.

Dans cette perspective, la récurrence de l'expression de ces éléments dans le discours des différents participants concrétise l'émergence d'une culture technique propre à la navigation sur voiliers volants.

\section{Méthode}

\subsection{Participants}

Douze pratiquants et praticiens de la navigation à la voile sur foils ont accepté de participer à cette étude. Chacun avait développé au cours des cinq dernières années une expérience et une expertise reconnues, relative à la pratique et à l'entraînement sur différents voiliers de compétition à foils (planche à voile, kitesurf, catamaran, monocoque de course au large), ou à la conception de tels voiliers. Ils avaient tous au moment de l'étude un engagement intensif dans le domaine de la voile volante, dans un cadre professionnel et/ou dans celui de la compétition de haut niveau. Les caractéristiques des participants sont présentées dans le Tableau 1. 
Tableau 1 : Caractéristiques des participants.

Table 1: Participants Characteristics

\begin{tabular}{|c|c|c|c|c|}
\hline Participants & Age & Sexe & Type de bateau & Eléments biographiques \\
\hline Participant 1 & 23 ans & \begin{tabular}{|l|l} 
Masculin \\
\end{tabular} & Catamaran volant & Équipage ayant participé au programme de \\
\hline Participant 2 & 24 ans & Masculin & Catamaran volant & $\begin{array}{l}\text { formation "Team France Jeune }{ }^{1} \text { Ces deux } \\
\text { participants ont également intégré l'équipage de } \\
\text { l'équipage Française à la "Youth America's } \\
\text { Cup » en } 2017 \text {. Y. }\end{array}$ \\
\hline Participant 3 & 22 ans & \begin{tabular}{|l|l} 
Masculin \\
\end{tabular} & Catamaran volant & Équipage ayant participé au programme de \\
\hline Participant 4 & 23 ans & \begin{tabular}{|l} 
Masculin \\
\end{tabular} & Catamaran volant & formation «Team France Jeune $»$. \\
\hline Participant 5 & 21 ans & Féminin & Catamaran volant & $\begin{array}{l}\text { Barreuse ayant participé au programme de } \\
\text { formation « Team France Jeune } » \text {. }\end{array}$ \\
\hline Participant 6 & 20 ans & Masculin & Catamaran volant & $\begin{array}{l}\text { Barreur ayant participé au programme de } \\
\text { formation « Team France Jeune » et est membre } \\
\text { de l'équipe de France de Nacra } 17 \text { (catamaran } \\
\text { volant). }\end{array}$ \\
\hline Participant 7 & 55 ans & Masculin & Catamaran volant & $\begin{array}{l}\text { Cadre technique sportif à l'Ecole Nationale de } \\
\text { Voile et des Sports Nautiques (ENVSN), } \\
\text { Entraîneur reconnu comme expert dans la } \\
\text { préparation d'quupages sur catamarans volants. } \\
\text { Entraîneur de l'équipe de France à la Youth } \\
\text { America's Cup en 2017, et en charge de la filière } \\
\text { d'entraînement sur catamaran à foils. }\end{array}$ \\
\hline Participant 8 & 24 ans & Masculin & Catamaran volant & $\begin{array}{l}\text { Educateur sportif reconnu dans l'encadrement en } \\
\text { catamaran volant, au sein d'une structure } \\
\text { pionnière dans l'enseignement de la navigation } \\
\text { volante destinée à un public non spécialiste. }\end{array}$ \\
\hline Participant 9 & 38 ans & Masculin & Skiff volant & $\begin{array}{l}\text { Régatier expert, deux fois médaillé aux } \\
\text { championnats d'Europe de Waszp. }\end{array}$ \\
\hline Participant 10 & 39 ans & Masculin & Windfoil & $\begin{array}{l}\text { Régatier expert, classé parmi les dix meilleurs } \\
\text { mondiaux sur le circuit professionnel de } \\
\text { Windfoil. }\end{array}$ \\
\hline Participant 11 & 44 ans & Masculin & Kitefoil, windfoil & 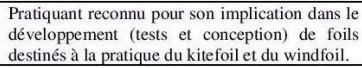 \\
\hline Participant 12 & 44 ans & \begin{tabular}{|l|} 
Masculin \\
\end{tabular} & Windfoil & $\begin{array}{l}\text { Pratiquant de windfoil reconnu pour son } \\
\text { implication pour son implication dans le projet } \\
\text { «Foil Generation ENVSN } »^{2}\end{array}$ \\
\hline
\end{tabular}

Ce programme de formation était destiné à de jeunes régatiers experts âgés de 18 à 25 ans et visait, à lissue d'un processus de sélection des candidats, à former la future élite française de la navigation sur catamaran volant. Le support principal utlilisé au cours de cette formation etait le Flying Phantom Elite (catamaran volant). 2Le projet "Foil Generation ENVSN" est destiné à accompagner l'émergence de la voile volante au sein de
structures d'entraînement.

\subsection{Recueil des données}

Des entretiens ont été conduits individuellement avec chaque participant. L'objectif était de favoriser une description la plus précise possible des expériences-types et des principes d'interprétation liés à la culture de chaque participant, relative à la stabilité de vol et aux conditions de son contrôle sur des voiliers à foils.

Nous avons mis en œuvre un format d'entretien ad hoc que nous avons qualifié d'entretien de partage d'expérience. Ces entretiens visaient la verbalisation de connaissances issues des expériences passées de l'acteur au cours de son activité relative à la voile volante. Il s'agissait de susciter un discours adressé à un interlocuteur pouvant être considéré comme un "pair-enquêteur " (auteur principal de l'article) : pair pour avoir développé lui-même une expertise pratique dans le domaine de la navigation sur des supports à foils; enquêteur pour avoir été formé aux techniques d'entretiens compréhensifs, d'explicitation et de remise en situation dans le cadre de recherches antérieures, conduites dans le programme de recherche du cours d'action. Le chercheur était par ailleurs familier des participants pour les avoir côtoyés à maintes reprises dans diverses situations liées à la pratique de la voile volante. Ces caractéristiques lui ouvraient la possibilité de maximaliser les bénéfices du jeu proximité/distance dans la construction des données (Theureau, 2006). Il s'agissait en effet de faciliter l'expression par les participants de dimensions non triviales de leur pratique avec leur propre vocabulaire technique, tout en effectuant des relances permettant d'obtenir de la finesse dans la description par les participants des actions et situations auxquelles sont indexées leurs connaissances. 
Pour chacun des douze entretiens, une démarche similaire a été mise en œuvre. En introduction, nous informions les participants que nous souhaitions « échanger autour de la notion de stabilité de vol », que la durée de l'entretien serait d'environ $45 \mathrm{mn}$ et que cet entretien prendrait la forme d'une conversation au cours de laquelle ils seraient invités à décrire leurs expériences de navigation sur bateau volant. L'entretien débutait avec la question suivante : " quelle importance accordes-tu à la stabilité de vol dans ta pratique, et que représente pour toi un vol stable, ou un vol instable? ». Cette amorce visait à produire un ancrage à partir duquel le participant pouvait s'engager dans l'entretien en mobilisant des connaissances relatives à la notion de stabilité de vol. La conduite de l'entretien a ensuite visé l'explicitation des situations ou moments précis décrits par les participants, grâce à un questionnement visant une évocation précise des contextes et de l'activité des participants dans ces situations, et à des relances inspirées de la méthode de l'entretien d'explicitation (Vermersch, 1994). Puis, sur la base de l'explicitation de moments particuliers traduisant des phénomènes significatifs pour les participants liés à la stabilité de vol, le chercheur incitait les participants à interpréter ces moments, et/ou à les comparer à d'autres moments jugés similaires ou différents du point de vue de ces phénomènes. Les relances du chercheur consistaient à approfondir l'explicitation de l'expérience des participants, par exemple, grâce à des relances invitant les participants à décrire plus précisément leurs actions, ressentis, préoccupations, focalisations dans ce type de situation. Le questionnement et les relances visaient également à amener les participants à contraster les différentes situations qu'ils décrivaient. Par exemple, après que le participant eut explicité un moment de vol stable, il pouvait être invité à décrire un moment de vol instable, puis à décrire des situations de transition entre des moments de vol stables et instables. Ces entretiens ont duré entre $20 \mathrm{mn}$ et $60 \mathrm{mn}$ selon les participants (moyenne $=30 \mathrm{mn}$ ).

\subsection{Analyse des entretiens}

Les entretiens, d'une durée cumulée de 6 heures, ont été retranscrits manuellement dans leur intégralité. Les protocoles verbaux ont ensuite fait l'objet d'une analyse systématique suivant deux étapes principales: (a) l'identification et la catégorisation des expériences-types évoquées par les participants à propos de la stabilité de vol et de son contrôle; (b) l'identification et l'analyse des principes d'interprétation mobilisés par les participants pour expliquer les phénomènes liés à la stabilité de vol et aux conditions de son contrôle. Pour cette seconde étape d'analyse, nous avons sélectionné les entretiens de six participants 5, 6, 7, 8, 9 et 11, qui présentaient des profils variés en termes d'expériences (régatiers, entraîneur, moniteur, concepteur) et de supports de navigation (catamaran, skiff, kitefoil, windfoil).

\subsubsection{Identification et catégorisation des expériences-types}

Dans un premier temps nous avons identifié et isolé dans les discours des participants l'ensemble des fragments de verbalisations permettant la délimitation d'une "expérience-type ». Ces expériences-types permettaient au pratiquant de distinguer ou d'associer, selon un étiquetage langagier particulier, les différentes expériences vécues selon leurs similitudes ou différences de son point de vue. Ces expériences-types pouvaient ainsi se rapporter à diverses composantes de l'expérience des participants. Il pouvait s'agir d'actions-types (ex. «se déplacer pour contrôler 
l'assiette longitudinale »), de situations-types (ex. «au portant dans les vagues »), de jugements perceptifs-types (ex. «bateau facile à la barre»), d'émotions-types (ex. "peur de se blesser»), associés à la reconnaissance d'un état du vol (stable/ instable) ou à l'activité de contrôle et de régulation de la stabilité de vol par les participants.

Ces expériences-types ont ensuite fait l'objet d'une catégorisation guidée par les questions de recherche, en relation avec deux axes d'analyse: (a) les éléments de reconnaissance et de distinction par les participants des expériences-types respectivement associées à un vol stable et à un vol instable; (b) les expériences-types relatives à l'activité de contrôle et de la régulation de la stabilité de vol (i.e., actions sur les commandes, déplacements, communications, visant à agir sur le comportement du bateau).

\subsubsection{Identification et analyse des principes d'interprétation mobilisés}

L'analyse des principes d'interprétations mobilisés par les participants a été conduite grâce à l'identification systématique des chaînes interprétatives identifiables dans le discours des participants pour expliquer les phénomènes liés à la stabilité de vol et aux conditions de son contrôle. Nous avons analysé le contenu de chaque principe d'interprétation en termes de relations entre des «conditions » et des « effets » telles qu'ils étaient évoqués par les participants au cours des entretiens, lorsque leur discours rendait compte d'interprétations particulières de telles relations et de leur direction (ex. entre des causes et des effets, des antécédents et des conséquences). Ces notions de « conditions » et d'« effets » sont inhérentes au point de vue de l'acteur, et ne renvoient aucunement à une interprétation de ces relations par le chercheur autre que le repérage de ces relations dans le discours des participants. Elles peuvent dans cette perspective être rapprochées des notions de contraintes et d'effets extrinsèques relatifs à certaines caractéristiques de la situation, du corps et de la culture, dans le programme de recherche du cours d'action (Theureau, 2004).

24 Le premier temps de cette analyse a consisté à identifier les éléments évoqués par les participants en termes de conditions, et en termes d'effets, puis à regrouper ces éléments dans des catégories plus générales, grâce à une démarche de catégorisation thématique inductive (Strauss \& Corbin, 1990). Cette démarche se distingue des démarches hypothético-déductives recourant à des catégories préexistantes à la recherche. Les catégories émergent au contraire de l'analyse grâce à une procédure de comparaison constante entre des "unités de sens" (ici des expériences-types élémentaires), qui sont progressivement regroupées selon un critère de similitude thématique. Cette procédure itérative conduit à formaliser un ensemble structuré de catégories s'étageant sur différents rangs. Les expériences-types relevant d'un même thème ont été regroupées dans 54 catégories de premier niveau, puis les catégories de premier niveau ont été regroupées en huit catégories de second niveau. Par exemple, les expériences-types «border ${ }^{4}$ la grand-voile» et "s'avancer sur le bateau » ont respectivement été catégorisées dans des catégories de premier niveau associées à la "régulation de la voile» et à la "mobilité de l'équipage», puis regroupées dans la même catégorie de deuxième niveau « mobilisation des commandes ".

Dans un second temps, les principes d'interprétations ont été reconstruits et codés à partir des relations conditions - effets au niveau des catégories de deuxième niveau. Cette analyse visait à identifier les relations entre catégories s'exprimant chez les six 
participants sélectionnés pour cette analyse. Nous avons ensuite construit des réseaux de relations entre catégories pour chaque participant (Figure 1) : chaque catégorie a été considérée comme un nœud du réseau, et les liens entre les nœuds sont basés sur l'existence d'une relation condition-effet entre deux catégories dans le discours du participant. Cette démarche est présentée dans le tableau 2.

Tableau 2 : Présentation de la méthode d'identification et d'analyse des principes d'interprétations à partir d'un extrait d'entretien du participant 8. Les catégories BAT (comportement du bateau) ; CMD (mobilisation des commandes); et MEC (éléments et phénomènes mécaniques) sont décrites dans la partie 4.2.1.

Table 2: Presentation of the method of identification and analysis of the principles of interpretation based on an extract from the interview of participant 8. The BAT (boat behavior), CMD (mobilization of controls) and MEC (mechanical elements and phenomena) categories are described in section 4.2.1

\begin{tabular}{|c|c|c|c|}
\hline \multicolumn{4}{|c|}{$\begin{array}{l}\text { Extrait d'entretien du Participant } 8 \text { : « Sur le cata[maran volant] la stabilité je trouve est un peu plus } \\
\text { compliquée en tout cas sur nous nos bateaux du fait qu'on est assis au rappel et non au trapèze on a } \\
\text { beaucoup plus de mobilité [lorsqu'on est au trapèze], à ça s'ajoute aussi le fait que le rake est pas } \\
\text { réglable en navigation, enfin est réglable à l'arrêt mais pas en dynamique, enfin a priori sur les Elites } \\
\text { [un autre modèle de catamaran volant équipé d'une configuration de foils différent le rendant plus } \\
\text { performant mais aussi plus technique] ils règlent pas tellement en dynamique finalement j'avais posé la } \\
\text { question au coach là il me disait que pas tellement finalement, c'était plus sur le mouvement de } \\
\text { l'équipage et du coup c'est ça qui fait que c'est un petit peu plus compliqué » }\end{array}$} \\
\hline $\begin{array}{l}\text { Identification d'éléments } \\
\text { " conditions » et } \\
\text { d'éléments « effets" }\end{array}$ & $\begin{array}{l}\text { Conditions-effets après } \\
\text { catégorisation de } \\
\text { premier niveau }\end{array}$ & $\begin{array}{l}\text { Condition-effets } \\
\text { après catégorisation } \\
\text { de deuxième niveau }\end{array}$ & $\begin{array}{l}\text { Début de construction d'un } \\
\text { réseau de relations entre } \\
\text { catégories }\end{array}$ \\
\hline $\begin{array}{l}\text { Être assis au lieu d'être } \\
\text { au trapèze (condition) } \\
\text { complique la } \\
\text { stabilisation (effet) }\end{array}$ & $\begin{array}{l}\text { Conditions : mobilité } \\
\text { de l'équipage } \\
\text { Effet : stabilité du } \\
\text { bateau }\end{array}$ & $\begin{array}{l}\text { Condition-effet } \\
\text { CMD-BAT }\end{array}$ & \\
\hline $\begin{array}{l}\text { Le fait de ne pas pouvoir } \\
\text { régler les foils en } \\
\text { dynamique (condition) } \\
\text { limite la capacité à } \\
\text { pouvoir stabiliser le } \\
\text { bateau (effet) }\end{array}$ & $\begin{array}{l}\text { Condition : réglage des } \\
\text { foils } \\
\text { Effet : stabilité du } \\
\text { bateau }\end{array}$ & $\begin{array}{l}\text { Condition-effet } \\
\text { MEC-BAT }\end{array}$ & \\
\hline $\begin{array}{l}\text { Si les foils ne se } \\
\text { régulent pas en } \\
\text { dynamique (condition), } \\
\text { cette régulation repose } \\
\text { sur le mouvement de } \\
\text { l'équipage (effet) }\end{array}$ & $\begin{array}{l}\text { Condition : Réglage } \\
\text { des foils } \\
\text { Effet : requiert une } \\
\text { mobilité de l'équipage }\end{array}$ & $\begin{array}{l}\text { Condition-effet } \\
\text { MEC-CMD }\end{array}$ & \\
\hline
\end{tabular}

\section{Résultats}

26 Les résultats sont présentés dans deux sections. La première décrit et caractérise les expériences-types associées par les participants à la stabilité de vol et à son contrôle ; la deuxième les principes d'interprétation mobilisés, relatifs aux états de stabilité de vol et à l'efficacité de son contrôle.

\subsection{Expériences-types associées à la stabilité de vol et à son contrôle}

Les expériences-types évoquées par les participants se rattachaient à deux catégories générales. La première concernait la reconnaissance d'états contrastés de stabilité du bateau, eux-mêmes étroitement associés à des jugements de qualité de vol (vol 
«stable " versus vol «instable »). La deuxième catégorie concernait les expériencestypes relatives aux actions de contrôle et de régulation de la stabilité de vol.

\subsubsection{La reconnaissance d'états contrastés de stabilité et de qualité de vol : des configurations perceptives et émotionnelles saillantes} les participants par des émotions plaisantes liées à des jugements de facilité de contrôle et de maîtrise du bateau. Ces expériences étaient évoquées dans des termes tels que : "on est un peu sur notre petit nuage quand c'est stable et que tout va bien»; "je me sens maitre du bateau (...) j'ai pas peur, il n'y a aucune frayeur, c'est vraiment la situation est maîtrisée " (Participante 5). Les participants décrivaient la sensation d'avoir "moins besoin d'agir sur le bateau " lorsqu'il était stable: "tu vois le bateau tu sens dans ton feeling à la barre et tout ça, hop, d'un coup le bateau t'as moins besoin d'en faire" (Participant 6). Le bateau était jugé «facile », « tolérant » : «tu sens que t'as de la tolérance, c'est-à-dire que tu sens que ton foil va accepter des petites erreurs, mais tu peux les rattraper facilement. C'est vraiment cette facilité de correction qui fait la stabilité" (Participant 11). Ces sensations intégraient parfois d'autres registres perceptifs, associant notamment la stabilité de vol à un paysage sonore silencieux : «dès qu'il est calé [en vol] t'as quasiment plus de bruit »(Participant 8).

En deuxième lieu, ces expériences-types intégraient de façon prégnante chez les participants des sensations relatives à «l'équilibre du bateau ». Celles-ci renvoyaient dans leurs propos conjointement à la perception (a) d'un équilibre directionnel du bateau (le bateau « va tout droit »), (b) d'une faible variabilité de son assiette latérale et longitudinale (le bateau est «calé»), et (c) d'une orientation optimale des forces propulsives :

«quand ton bateau il est bien équilibré (...) tu peux lâcher la barre et tu régules juste ton écoute de GV [grand-voile] quoi, tu vois et le bateau il va tout droit, et c'est trop bien » (Participant 9);

«t'as de la pression vraiment dans le bateau quoi. Tu sens que toute la force vélique est transformée [en vitesse] » (Participant 6).

Se plaçant du point de vue d'un observateur extérieur (celui d'un entraîneur), l'un des participants a évoqué ce qui lui semblait être l'indice principal d'une stabilité: un bateau qui navigue sans "coups de gite» ou de "contre-gite», et dont l'assiette longitudinale reste horizontale indépendamment des variations de hauteur de vol, c'est-à-dire qui « redescende à l'horizontale et qui décolle à l'horizontale » (Participant 7).

En troisième lieu, la description d'une expérience de vol stable était associée par les participants à la possibilité de pouvoir décentrer leur attention des actions de pilotage $\mathrm{du}$ bateau, et être plus disponibles pour prendre des informations dans l'environnement du bateau, en particulier dans les situations de régate :

«t'as moins besoin de te concentrer sur la propreté de ton vol (...) et du coup tu peux sortir un peu la tête du bateau et regarder tous les aspects tactiques qui en découlent, le vent, les adversaires tout ça » (Participant 6) ; « une fois que t'es calé normalement tu regardes autour de toi » (participant 10).

31 Toutefois, certains participants ont évoqué des cas dans lesquels l'expérience d'un vol stable pouvait être associée à la perception d'une vitesse relativement limitée du bateau en comparaison de ses possibilités estimées dans la situation. Un exemple typique a été décrit par le Participant 9 , naviguant sur un bateau doté d'un système 
d'asservissement réglé pour être très réactif aux variations de hauteur de vol, et qui était donc pour lui « très stable, mais pas rapide (...) c'est très stable parce qu'il [ne] va jamais rien se passer en fait, tu vas jamais planter [mais] dès qu'il y a une vague un peu plus haute le bateau il va monter, une vague plus basse il va descendre, et il y a des moments [où] t'as envie de gagner vers l'avant [en traversant les vagues]». La Participante 5 a de son côté décrit l'expérience d'une voile trop bordée, générant chez elle "des sensations au niveau des fesses qu'on vole, qu'on est stable, mais qu'on n'accélère pas». Les participants 1 et 2 associent cette expérience aussi bien à un réglage de foil trop extrême qu'à une voile trop « bordée » :

«Typiquement tu fais un portant ou il y a un peu de vent quand même, tu mets full rake [réglage maximal de l'angle d'incidence du foil], ton bateau il va être super stable, mais par contre il sera pas très vite quoi (participant 2), ou même de surborder le spi comme tout à l'heure ça te crée de la stabilité de fou, mais après t'es plus performant » (participant 1$) »$.

Ainsi ces participants pointaient des éventualités circonstancielles de vol stable associées à des modes de fonctionnement peu performants du bateau.

Les expériences-types associées à un vol instable se caractérisaient en premier lieu par des sentiments traduisant des émotions déplaisantes chez les participants, qui étaient étroitement liées à des jugements perceptifs relatifs à une certaine difficulté à contrôler le bateau. Ces expériences étaient évoquées dans des termes tels que :

«[c'est] une sensation beaucoup moins agréable, parce que là (...) on [ne] maîtrise plus, enfin moins... la chose, et c'est vraiment pas agréable de pas maitriser quelque chose » (Participante 5).

Le comportement du bateau était décrit comme «volage» (Participante 5), ne se comportant pas conformément aux attentes de l'équipage: "ton bateau il va commencer à descendre alors qu'il fallait qu'il monte donc il va toucher, tu vois » (Participant 9). Se plaçant du point de vue d'un observateur extérieur (celui d'un entraîneur), l'un des participants a évoqué ce qui lui semblait être les indices principaux de l'instabilité: un bateau qui «bouge dans tous les sens», qui «cabre quand il accélère ", sur lequel l'équipage doit « beaucoup bouger » (Participant 7).

En deuxième lieu, ces expériences-types intégraient de façon prégnante chez les participants des perceptions kinesthésiques ou sonores traduisant des perturbations du fonctionnement hydrodynamique des foils. Ils évoquaient par exemple la sensation d'une barre qui "guidonne " (Participant 6), ou des vibrations et bruits caractéristiques, comme ceux décrits par le participant 8 à propos d'un vol instable à faible vitesse :

« tu sens que ton foil il peine à te garder en l'air (...) c'est une espèce de bruit sourd et surtout tu le vois parce que t'as plein de flotte enfin t'as des gros mouvements d'eau sous tes fesses ".

En troisième lieu, ces expériences-types de vol instable lorsqu'elles étaient associées à des moments de navigation à grande vitesse, intégraient des sentiments de peur ou d'appréhension parfois très marqués, en particulier dans des conditions de vent irrégulier ou de vagues formées : "notre hantise sur les bateaux volants c'est les vagues" (Participant 6). Ces sentiments étaient associés à des anticipations de bris de matériel, de blessures, ou de conséquences pénalisantes d'un amerrissage incontrôlé lors d'une régate (brutale décélération pouvant s'accompagner d'un chavirage du bateau) :

« tu te retrouves dans une situation plus stressante (...) si t'as vraiment une perte de contrôle qui te fait peur, parce que ça peut arriver des pertes de contrôle qui sont violentes tu vas te retrouver dans une situation où tu vas pas être en confiance » (Participant 11). 
Ces résultats mettent en évidence une reconnaissance d'états contrastés de stabilité et de qualité de vol par les participants, fondée sur des configurations d'expériences perceptives et émotionnelles saillantes, prenant pour les participants un caractère prototypique. Du point de vue des registres sensoriels, ils pointent également la prégnance des jugements proprioceptifs et auditifs dans ces configurations.

\subsubsection{Le contrôle et la régulation de la stabilité de vol : la restauration permanente d'un compromis constamment menacé}

Les expériences-types décrites par les pratiquants traduisaient des modalités de contrôle différenciées selon que l'effet recherché concernait le contrôle de l'assiette longitudinale ou latérale, ou encore l'équilibre directionnel global du bateau. Ainsi, le contrôle de l'assiette longitudinale est associé aux déplacements longitudinaux de l'équipage et aux réglages des foils :

«sur le Phantom [catamaran à foil] c'est l'équipier qui fait le rake [modifie l'angle d'incidence du foil], qui fait la régulation du longi [l'assiette longitudinale], tu vois en fait il s'avance hop ça remet [le bateau à plat] » (participant 9).

Le contrôle de l'assiette latérale est quant à lui associé aux actions sur les voiles et à la régulation de la trajectoire à la barre :

« Pour moi la stabilité latérale là (...) je vois que le bateau j'arrive pas à le contrôler, il fait un peu je gite j'arrête de giter, je me dis peut-être qu'il faut que je trouve un angle intermédiaire, là dans ce cas-là je suis un peu trop extrême dans mes mouvements de barre. » (participante 5).

Autrement dit, du point de vue des participants, le contrôle de l'assiette longitudinale était essentiellement lié à des actions sur les plans porteurs immergés (les foils) et/ou à des déplacements sur le bateau. De même, le contrôle de l'assiette latérale était principalement lié à des actions sur les plans propulseurs aériens (les voiles) et/ou à des modifications de trajectoire du bateau. La focalisation des pratiquants sur les étraves du bateau était conçue comme l'un des indices essentiels de l'efficacité de ces actions, comme en témoigne l'extrait d'entretien suivant :

« en regardant les étraves, comment elles travaillent, en regardant, effectivement si quand tu te déplaces en avant pour le recaler et que tu vois qu'il [ne] se passe rien

(...) tu sais que t'arriveras pas à le récupérer [le bateau] » (participant 8).

Ce contrôle était associé à deux intentions antagonistes: (a) agir moins (limiter les effets de ses actions sur le bateau) : "à la barre j'essaye d'avoir une conduite un peu plus souple, un peu plus ample» (Participant 6); ou (b) agir plus (amplifier les effets de ses actions sur le bateau) "l'équipier il s'avance tout ce qu'il peut et quand il [ne] peut plus s'avancer il brutalise un peu le bateau quoi, il met des coups de pieds sur l'avant pour remettre le bateau dans ses lignes" (Participant 6). La demande attentionnelle et physique de ces actions de contrôle était soulignée par les participants «t'es obligé d'être vigilant tout le temps (...) c'est un truc hyper important donc ça prend pas mal d'énergie, après l'autre truc c'est que physiquement c'est hyper dur quoi, t'as des crampes aux avant-bras (...), aux jambes" (Participant 9).

Le contrôle de la stabilité longitudinale était présenté par les participants comme mis à l'épreuve par deux sources de perturbation particulières : le passage dans les vagues et les accélérations du bateau. Celles-ci étaient associées à des modalités de contrôle ayant en commun l'intention sous-jacente de conserver le foil immergé et le bateau en vol. Lors du passage du bateau dans une vague le foil à tendance à poursuivre sa trajectoire. En l'absence d'actions de l'équipage ou de mécanismes d'asservissement pouvant 
équiper certains bateaux, cela engendre une diminution temporaire de la hauteur de vol lors du passage de vague, et une augmentation temporaire de la hauteur de vol lors du passage dans le creux des vagues. Les accélérations modifient quant à elles la portance des foils. En l'absence d'actions de l'équipage ou de mécanismes d'asservissement, elles produisent une «montée» du bateau (a contrario les décélérations provoquent une «descente » du bateau). Le contrôle du bateau dans les vagues comme dans les accélérations suppose donc la combinaison d'actions visant à contrôler conjointement les variations de hauteur du bateau et les variations de puissance dans les voiles. Pour les participants, cela exigeait, d'une part, des réglages des foils adaptés aux conditions de vent et de mer : «un réglage 'bow down' [réglage du mécanisme d'asservissement pour que le bateau vole "bas»] c'est très dur à tenir dans les vagues, parce que tu peux enfourner d'un coup» (Participant 6), "tu descends un peu la baguette en fait tu vas plus bas (...) c'est juste pour éviter quand il y a des trous de sortir » (Participant 9). Cela imposait, d'autre part, des actions complexes de conduite, de déplacements longitudinaux et de bordés/choqués de voile. Ces actions pouvaient être combinées dans le cas de la navigation en solitaire "en gros tu vas border fort pour descendre la vague et essayer que ça colle et une fois que le bateau hop il s'est remis dans ses lignes hop tu rechoques et tu réaccélères (...) en termes de position quand tu vois que ça va merder (...) tu recules pour faire lever le nez» (Participant 9), ou partiellement dissociées dans le cas de navigation en double «à la barre tu places le bateau dans les vagues et l'équipier il les contre ces vagues» (Participant 6).

De plus, les expériences-types décrites par les pratiquants, associées aux actions de contrôle et de régulation du vol traduisaient une recherche de compromis " prise de risque/stabilité ». La recherche de vitesse sur les supports à foil est associée à la stabilité du vol d'une façon paradoxale: d'une part, il est nécessaire que le vol soit stable pour que le bateau aille vite; d'autre part chercher à faire accélérer le bateau déstabilise le vol et accroit le risque de décrochage des foils (engendrant une retombée brutale du bateau, ou "crash»). Ainsi, les participants ont évoqué une recherche permanente de compromis entre la prise de risque de déstabiliser le vol en allant plus vite, et le contrôle de la stabilité de vol à vitesse moindre. Cette prise de risque était étroitement associée aux conséquences d'un éventuel «crash» (blessures ou bris de matériel) :

« ça va tellement vite sur ces bateaux-là qu'on a toujours peur de se blesser, et là je pense on pense toujours matériel, mais on pense beaucoup aussi à soi» (Participante 5).

Elle pouvait aussi bien être associée à la perte de positions en régate :

« des fois tu prends le risque d'aller un peu moins vite que le copain, mais [cela permet] d'assurer le fait d'arriver en bas quoi, voilà c'est un compromis à faire » (Participant 9).

Pour certains participants, il s'agit de «trouver cette petite limite au maximum sans se mettre en danger " (Participante 5), ce qui suppose dans certain cas de modifier les réglages ou d'adapter son comportement afin de limiter la capacité du bateau à accélérer "dès qu'il y a de la mer formée ça devient beaucoup plus technique et la moindre erreur de déplacement peut se payer cash (...) on diminue un peu la puissance du bateau et sa capacité à accélérer » (Participant 6). Pour autant, si la préoccupation des pratiquants était d'éviter les décrochages des foils, ils ont souligné que ces derniers pouvaient parfois être anticipés sans toutefois être contrôlés. La spécificité des expériences-types 
de décrochage est la soudaineté de leur apparition et l'impossibilité de rattraper un bateau qui décroche, ainsi que l'ont souligné certains participants :

« vu qu'il [le bateau] dérape comme ça [lors d'un décrochage] faut essayer d'aller dans le même sens, mais en général t'arrives pas vraiment à le rattraper (...) c'est déjà trop tard » (Participant 8) ;

« tu vois pas le truc venir et là tu prends une grosse boîte, des fois tu te dis bah là je vais me la prendre, mais souvent t'as pas le temps, souvent tu les prends sans les voir venir » (Participant 9);

«[dans le clapot] on peut vite se faire surprendre, avec une touchette [de la carène contre la surface de l'eau] on fait vite un arrêt buffet quoi » (participant 10).

Pour les participants, la réaction au décrochage ne peut alors consister qu'à laisser faire le bateau en espérant qu'il se restabilise de lui-même "t'essayes de faire corps avec le bateau pour que ça reparte " (Participant 9), ou à prévenir la violence de la décélération lors de l'impact des coques avec l'eau, pouvant se conclure par l'éjection de l'équipage «Tu te fais éjecter et tu ricoches sur l'eau » (Participant 9).

Les expériences types de contrôle du vol révèlent une recherche permanente de compromis entre « agir plus ou agir moins » pour stabiliser le bateau, et un compromis entre atteindre une vitesse maximale et limiter la prise de risque accompagnant cette recherche de vitesse. Cette recherche de compromis est constamment mise à l'épreuve par les variations de vent et de vagues. Les grandes vitesses atteintes par ces bateaux et les risques physiques et matériels associés à une perte de contrôle du vol marquent les expériences-types des pratiquants.

\subsection{Principes d'interprétation des états de stabilité de vol et de l'efficacité de son contrôle}

L'interprétation par les participants des états de stabilité de vol et de leurs variations consiste en la mise en relation de sept catégories d'éléments. Celles-ci ont été construites à partir de l'analyse des éléments mobilisés dans les chaînes interprétatives apparaissant dans le discours des participants, et qui étaient communes à l'ensemble des participants. Trois formes de relations entre les catégories d'éléments sont identifiables, formant un réseau d'éléments interdépendants, explicatifs des états de stabilité de vol du point de vue des participants.

\subsubsection{Les catégories d'éléments mobilisées par les participants pour interpréter les états de stabilité de vol et leurs variations}

Les sept catégories d'éléments mobilisés dans le discours des participants comme des " conditions » et/ou comme des « effets ", pour expliquer les états de stabilité de vol et leurs variations, concernent respectivement :

a. le comportement du bateau (BAT) : cette catégorie regroupe les différentes occurrences de comportements typiques $\mathrm{du}$ bateau en navigation. Elle concerne la spécification des variations d'assiette latérale ou longitudinale, de vitesse et de hauteur de vol ;

b. l'allure de navigation (CAP): cette catégorie regroupe les différentes spécifications des trajectoires du bateau par rapport au vent (ex. navigation au près, au largue, au travers) ;

c. la contrôlabilité du bateau (CNT) : cette catégorie regroupe les expériences des participants associées à leur capacité à contrôler le comportement du bateau. Elle concerne notamment la spécification de la «facilité » du bateau, du «risque » de perdre le contrôle et de la «pression temporelle»; 
d. l'environnement (ENV) : cette catégorie regroupe les variations de conditions de vent, de mer ou la présence ou non d'autres bateaux sur le plan d'eau ;

e. la mobilisation des commandes (CMD) : cette catégorie regroupe les actions dynamiques sur les commandes des voiliers (ex. écoutes des voiles, barre), ainsi que les déplacements ;

f. les spécificités mécaniques $(\mathrm{MEC})$ : cette catégorie regroupe les éléments mécaniques spécifiques des bateaux (ex. type de bateau, forme et réglages des foils, des voiles et du gréement, points d'applications des forces hydrodynamiques et aérodynamiques),

g. l'activité de l'équipage (ACT). Elle regroupe les éléments concernant l'activité perceptive et intentionnelle de l'équipage: les perceptions, les décisions et la communication de l'équipage.

Dans les discours des participants, ces catégories peuvent être associées pour expliquer les états de stabilité de vol et leurs variations. Elles forment ainsi des réseaux de relations que nous présentons dans la Figure 1.

\subsubsection{Des réseaux de catégories interdépendantes révélant une appréhension systémique de la stabilité de vol chez les participants}

Les résultats de l'analyse des relations entre les éléments ressortant des catégories mobilisées dans les chaînes interprétatives mettent en évidence: (a) des réseaux de relations entre catégories qui varient entre les participants; (b) trois formes de relations entre les catégories ; (c) une interdépendance des éléments mécaniques et liés à l'activité des pratiquants; et (d) le comportement du bateau comme élément explicatif de ses propres variations.

Les réseaux de relations mis au jour sont présentés dans la figure 1 . Chaque flèche correspond à l'expression d'une relation entre une catégorie de conditions et une catégorie d'effets dans les connaissances du participant. Par exemple pour la participante 5, la relation entre la catégorie ENV et la catégorie BAT est exprimée dans une seule direction condition-effet (flèche allant de ENV vers BAT), la relation entre les catégories BAT et ACT est exprimée dans les deux directions (flèche allant de BAT vers ACT et flèche allant de ACT vers BAT), et la relation de la catégorie BAT avec elle-même est exprimée par une boucle rétroactive (boucle partant de, et revenant à BAT). En revanche, pour cette participante la relation entre ENV et CMD n'a pas été exprimée, tandis qu'elle le fut par exemple pour les participants 6 et 7 .

L'analyse des relations entre catégories met en évidence des réseaux variés de relations entre éléments explicatifs des états de stabilité de vol chez les six participants. Cette variété s'exprime par le nombre de mises en relations, allant de 11 relations entre catégories pour le participant 11, à 28 relations entre catégories pour le participant 7 . 
Figure 1 : Représentation graphique des relations entre les catégories mobilisées dans les chaînes interprétatives pour les participants $5,6,7,8,9$ et 11 . BAT : comportement du bateau ; CAP : allure de navigation ; CNT : perception de la contrôlabilité du bateau ; ENV : variations du vent, état de la mer, obstacle ; CMD : mobilisation des commandes ; MEC : éléments et phénomènes mécaniques ; ACT : activité perceptive et intentionnelle de l'équipage.

Figure 1: Graphical representation of the relationships between the categories mobilized in the interpretative chains for participants 5, 6, 7, 8, 9 and 11. BAT: behavior of the boat; CAP: point of sail; CNT: perception of the boat's controllability; ENV: wind variations, sea state, obstacle; CMD: mobilization of controls; MEC: mechanical elements and phenomena; ACT: Perceptual and intentional activity of the crewmembers

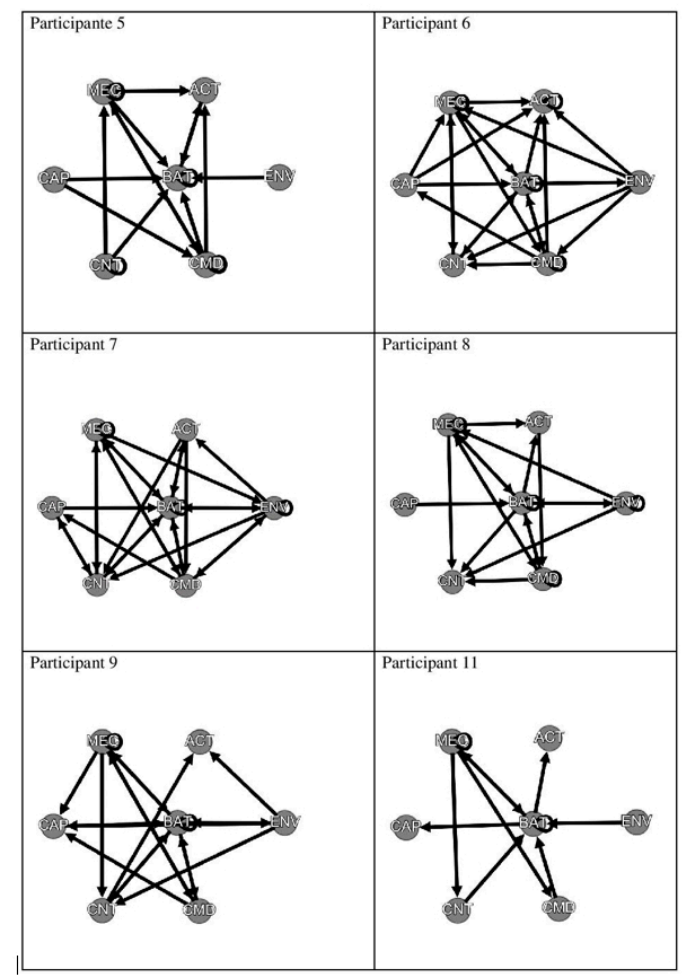

Cette variété s'exprime aussi par la diversité des formes de mises en relation entre ces éléments. Les relations entre catégories prennent en effet trois formes différentes :

- Unidirectionnelles : les relations unidirectionnelles apparaissent lorsque les relations entre des conditions et des effets n'existent que dans la direction condition - effet. Par exemple la catégorie CAP n'entretient que des relations unidirectionnelles avec la catégorie BAT pour les participants 5, 6,7, 8 et 11 .

- Réciproques : les relations réciproques apparaissent lorsque la relation entre condition et effet apparaît dans les deux directions. Une catégorie peut regrouper des conditions en relation avec une catégorie d'effets, cette catégorie étant à son tour condition de la première. Par exemple, les participants $6,7,8,9$ et 11 expriment une relation réciproque entre les catégories BAT et MEC.

- Rétroactive (ou en boucle fermée) : les relations rétroactives apparaissent lorsqu'une même catégorie est condition d'un effet sur elle-même. Par exemple, des relations rétroactives sont exprimées par l'ensemble des participants pour la catégorie BAT et la catégorie MEC (Tableau 2).

Cette variété entre les réseaux des différents participants traduit des cultures propres différentes, que nous pouvons attribuer à la variété des profils des participants et des supports utilisés (ex. en double ou en solitaire, en position assise ou au trapèze ou debout sur une planche, avec plus ou moins de possibilités de réglages sur le bateau, 
etc.). En contrepartie, les relations entre catégories que l'on retrouve de manière consensuelle chez plusieurs participants traduisent le potentiel d'émergence d'une culture partagée. L'analyse de ces relations met également en évidence une interdépendance entre les dimensions mécaniques (MEC) et l'activité de l'équipage considérée au sens large c'est-à-dire incluant les catégories ACT, CMD et CNT, par l'intermédiaire des comportements du bateau (BAT). En particulier, la médiation de la catégorie BAT apparait systématiquement entre les catégories CMD et MEC. Autrement dit, pour les participants, les variations des dimensions mécaniques du bateau conditionnent l'activité de l'équipage (ex. une modification du réglage des foils explique une modification de la position de l'équipage), et réciproquement, l'activité de l'équipage engendre des effets mécaniques sur le bateau (ex. un changement de position de l'équipage modifie les points d'applications des forces mécaniques s'exerçant sur les foils et le gréement).

Enfin, du point de vue des participants, le comportement du bateau est un élément explicatif systématique des variations de comportement du bateau (et il en est de même pour le fonctionnement mécanique - aérodynamique et hydrodynamique - du bateau). Par exemple, une variation d'assiette du bateau produit une variation de la vitesse du bateau, qui produit une variation des assiettes. De plus, la catégorie BAT est toujours en relation avec l'environnement, et pour les participants 7, 8 et 9 cette relation est réciproque. Ils considèrent que l'environnement conditionne le comportement du bateau (ex. une augmentation de la force du vent réel modifie la vitesse et/ou les assiettes $\mathrm{du}$ bateau), et qu'en retour, le comportement du bateau modifie son environnement (ex. une augmentation de la vitesse du bateau modifie les conditions environnementales en provoquant une variation du vent apparent).

Ces résultats mettent en évidence que la stabilité de vol du point de vue des participants est associée à des expériences-types de reconnaissance du comportement du bateau et de son contrôle, imprégnées de dimensions sensorielles et émotionnelles. L'analyse des principes d'interprétations met par ailleurs en évidence un consensus exprimé par les participants sur le caractère complexe et multifactoriel de la stabilité de vol.

\section{Discussion}

Cette étude visait à appréhender l'émergence d'une culture technique propre à un nouveau mode de navigation à voile, la navigation volante, en interrogeant les connaissances de pratiquants et praticiens "pionniers » de ce mode de navigation, relatives à la notion de stabilité de vol.

\subsection{La stabilité du vol : un phénomène complexe échappant au modèle explicatif classique de la performance des voiliers dans la littérature technique}

51 Les résultats portant sur les principes d'interprétation mettent en évidence que du point de vue des connaissances des participants, la stabilité du vol d'un voilier à foil est un état précaire qui émerge d'un réseau hybride d'éléments respectivement associés au système mécanique considéré, à l'équipage et à la situation de navigation. Le système 
de relations mis en évidence dans le discours des participants diffère, de ce point de vue, du modèle explicatif qui prévaut classiquement dans la documentation technique du domaine, et mobilisé dans la formation des régatiers et des entraîneurs en voile. Ce modèle, considérant la voile comme un "sport mécanique", pose en effet les conditions physiques de la performance des voiliers (aérodynamiques et hydrodynamiques) comme des conditions fondamentales à respecter par les pratiquants, grâce à leur mobilisation des commandes et des réglages du voilier, cette mobilisation dépendant elle-même de comportements appropriés (ex. Chéret, 2006 ; Gouard, 1988 ; Saury, 1990). Ainsi, ce modèle postule des relations causales linéaires entre (a) les comportements et l'activité de l'équipage, (b) leurs conséquences en termes de mobilisation des commandes et des réglages, et (c) leurs effets sur les comportements et les performances du bateau (du fait des «lois » aérodynamiques et hydrodynamiques expliquant le fonctionnement d'un voilier).

La complexité du fonctionnement des voiliers à foils, telle qu'elle apparaît dans les principes d'interprétation de la stabilité de vol mobilisés par les participants s'exprime également par la rétroactivité des effets du comportement du bateau sur son propre comportement, qu'ils évoquent dans leurs discours. De ce point de vue, le comportement du bateau n'est pas simplement commandé par l'équipage, mais une partie de ce comportement est liée à l'histoire de la relation dynamique entre le bateau, l'environnement et l'équipage. Bien que l'équipage par ses actions puisse modifier la relation entre le bateau et l'environnement, en agissant sur les voiles ou sur les réglages, l'effet de ces actions sur le comportement du bateau dépend non seulement de l'action effectuée et des conditions environnementales au moment de l'action, mais également $d u$ comportement du bateau à l'instant précédent. Le fonctionnement apparaît, de ce point de vue, dans le discours des participants, comme doté d'une propriété d'irréversibilité (un comportement nouveau émergeant à chaque instant à partir du comportement passé), et d'autonomie (le comportement du bateau à un instant donné n'est pas uniquement le produit de stimulations d'une source externe).

De plus, les expériences-types exprimées par les participants accréditent leur appréhension de la navigation sur des voiliers volants comme relevant du fonctionnement de systèmes auto-organisés. Ces expériences-types les amènent à associer le maintien de la stabilité de vol à une " mise en tension » du système bateau/ équipage, cette tension étant régulée par l'équipage qui doit à la fois être "maitre du bateau ", pour le contrôler et avoir des actions efficaces, mais en même temps « laisser vivre » le bateau pour que celui-ci ait une relation optimale avec son environnement. Cette tension est mise en évidence: (a) à travers les expériences-types de vol stable, mais non rapide, lorsque l'équipage configure le bateau de manière à accroitre son contrôle, au détriment de l'efficacité hydrodynamique et aérodynamique de celui-ci, et (b) lorsque le maintien de la stabilité suppose une augmentation des amplitudes de l'action de l'équipage. Dans ce cas, l'équipage «lutte » avec le bateau pour le maintenir à chaque instant dans ses lignes et éviter que le comportement de ce dernier ne compromette la viabilité du vol. L'augmentation ou la diminution de cette mise en tension modifient également la perception de l'environnement par l'équipage, qui est plus sensible à celui-ci lorsque cette tension diminue.

54 La navigation sur voilier volant semble donc être une navigation de compromis, entre « chercher à stabiliser le vol, mais sans atteindre la vitesse maximale possible pour le bateau » et « augmenter le potentiel de vitesse du bateau en acceptant de perturber la 
stabilité du vol». Cette recherche de compromis s'accompagne d'expériences-types ayant une tonalité émotionnelle significative pour les participants. La qualification de la stabilité de vol est ainsi associée à des sensations plus ou moins agréables. Si un bateau stable permet d'être sur "son petit nuage ", un bateau instable de son côté est associé à des émotions pouvant être qualifiées de "négatives" (i.e., peur, appréhension). L'expérience-type vécue par les pratiquants de bateaux qui "décrochent soudainement ", engendrant des dommages qui peuvent être de l'ordre du résultat en régate, mais également matériels et humains, participe nécessairement à la tonalité émotionnelle d'un vol à haute vitesse lorsque le contexte de navigation accroît les risques de perte de contrôle (ex. vagues, fortes variations de vent). Ces expériences-types résonnent avec la " culture du vertige », discutée par Lacombe (2002) à propos de l'évolution de la planche à voile : la relation avec le support ne se limiterait pas à une recherche d'angle optimal par rapport au vent pour optimiser la poussée vélique, mais se combinerait à une recherche de sensations procurant des émotions, parfois prégnantes dans l'activité. Cette dimension bien qu'existant implicitement dans l'activité, n'est à ce jour que peu formalisée dans les documents techniques de référence (ex. Chéret, 2006).

Les résultats de notre analyse nous permettent de suggérer que du point de vue des connaissances des participants la stabilité de vol est une forme de comportement du bateau qui émerge d'un processus dans lequel la relation entre l'équipage et le bateau ne se limite pas aux dimensions mécaniques de "mise en forme» du bateau par des actions sur les commandes, mais est une relation de codétermination d'opportunités d'actions entre l'équipage et le bateau, intégrant des dimensions émotionnelles, et émergeant de l'incorporation par l'équipage du comportement dynamique du bateau (Malafouris, 2019 ; Warnier, 1999).

\subsection{La voile volante comme révélateur de dimensions jusqu'alors implicites dans la culture technique de la voile légère}

56 Les résultats de nos analyses mettent en évidence des dimensions de l'activité de navigation jusqu'à présent peu formalisées dans les ouvrages techniques sur la navigation en voile légère. Bethwaite (2012) souligne que les connaissances des pratiquants en termes de conduite d'un bateau ont été jusqu'à récemment un «nonsujet ». Les expériences-types et les principes d'interprétation exprimés par les participants à cette étude soulignent en particulier la relative autonomie de la dynamique du comportement du bateau. D'un point de vue mécanique, ces expériences pourraient en partie être expliquées par certaines caractéristiques de la relation entre les voiliers et leur environnement physique (la masse d'eau et la masse d'air à l'interface desquels ils évoluent), qui sont modifiées par les évolutions technologiques permettant aux voiliers d'atteindre de très hautes vitesses (très supérieures à la vitesse du vent). De ce point de vue, Püschl (2018) évoque le cas du "high speed sailing". Celuici se traduit par la capacité des voiliers rapides (ex. voiliers volants) à s'extraire largement des contingences des variations hydrologiques (ex. courants), et des variations aérologiques (ex. variations du vent réel en force et en direction), en produisant "leur propre vent " (i.e., le vent apparent) grâce à leur vitesse de déplacement (Püschl, 2018). En effet, plus la vitesse du bateau est élevée, moins les variations de vent réel produisent de variation de vent apparent. Ainsi, comparativement à un voilier à déplacement plus classique, un voilier rapide accroît 
son autonomie par rapport à son environnement aérodynamique en créant son propre vent. De plus, en s'élevant au-dessus de l'eau, la relation entre le bateau porté par des foils et son environnement hydrologique est modifiée : lorsque la coque d'un bateau est en contact permanent avec l'eau, l'équilibre du bateau dépend de la surface du plan d'eau : « le passage d'une vague, modifiant la surface liquide, transforme la carène, et se faisant, déplace son centre [de carène] " (Chéret, 2006, p. 426); "la carène s'incline selon le dessin instantané de chaque vague » (Ibid., p. 429); en s'élevant sur les foils, l'équilibre du bateau n'est plus contraint pas la forme des vagues ni par les chocs du clapot, ceux-ci n'ayant pas d'influence directe sur la portance des foils. La portance des foils dépend de leur angle d'attaque, défini par les réglages et les assiettes du bateau et de la vitesse. Le voilier à foils accroît donc également son autonomie par rapport à son environnement hydrologique, en comparaison d'un voilier non volant.

Ainsi, dans le domaine de la voile légère, l'adjonction de foils sur les voiliers semble prolonger les évolutions technologiques observables au cours des dernières décennies, portant sur les formes de carènes, associées à l'utilisation de matériaux plus légers. Un voilier rapide et léger gagne en «autonomie relative» par rapport à son environnement physique, tout en devenant également dans le même temps plus sensible au comportement de l'équipage. Le caractère "saillant» de ces propriétés semble amplifié dans la navigation sur des voiliers à foils, ainsi que cela ressort de l'analyse des expériences-types et des principes d'interprétation de la stabilité de vol dans le discours des participants à cette étude. Notre analyse met au jour et spécifie les caractéristiques de l'« incorporation » de la dynamique du bateau par l'équipage. Cette incorporation de la « dynamique de l'objet » (Warnier, 1999) est déjà à l'œuvre en voile non volante, ainsi que le soulignent Julien et Rosselin $(2005$, p. 4) : « c'est en barrant, en marchant sur le pont, en choquant ou en bordant les voiles, en ressentant les interactions entre le corps qui agit et le bateau qui bouge que le bateau est progressivement incorporé ». Pour autant, on peut avancer l'hypothèse que cette dimension demeure essentiellement "en arrière-plan" des activités opératives de pilotage du bateau dans l'expérience des équipages sur des voiliers classiques, ainsi qu'en témoigne l'absence de sa thématisation dans la littérature technique (ex. Chéret, 2006). Nos résultats accréditent l'idée que celle-ci passe «au premier plan» dans l'expérience de navigation en voile volante. Par ailleurs, cette incorporation s'accompagne d'après notre analyse d'une dimension émotionnelle pleinement constitutive des jugements perceptifs et des expériences-types rapportés par les participants. Cette dimension a jusqu'à présent, également été peu décrite dans les ouvrages techniques de navigation en voile non volante. Nous avançons l'hypothèse que cette dimension est cependant implicitement présente dans l'expérience des pratiquants en voile "non volante", et plus particulièrement dans les conditions extrêmes de navigation (ex. vent très fort, mer très agitée), et/ou dans l'activité d'optimisation de leurs performances chez des compétiteurs de très haut niveau. Chéret (2006) cite par exemple Philippe Presti ${ }^{5}$ à propos de la technique de navigation pour descendre les vagues dans le vent fort en Laser $^{6}$ : "Si vous abattez en fausse panne, vous conservez le maximum de vitesse, donc le moins de pression sur la voile et c'est le grand pied : tout vibre, vous volez » (Chéret, 2006, p. 439). Dans ces conditions la recherche de compromis entre avoir un bateau tolérant ou avoir un bateau performant était également déjà présente, notamment pour «s'accommoder du désordre de la mer » (Chéret, 2006, p. 199). 


\section{Conclusion}

58 Cette étude était fondée sur deux prémisses essentielles. La première était que la voile sportive offrait, dans la période actuelle, une opportunité unique pour étudier les relations entre le développement d'innovations technologiques (dans le cas présent, l'équipement de foils pour une grande variété de voiliers), l'invention de nouvelles techniques sportives, et leur diffusion en tant qu'innovations dans une culture technique donnée. La deuxième était qu'il était possible d'approcher ce processus « en train de se faire » sur la base d'une analyse de l'expérience de pratiquants et praticiens pionniers de la navigation sur des voiliers volants. Il s'agissait plus particulièrement d'explorer les connaissances constitutives de cette expérience, susceptibles d'être partagées, et de faire - au moins potentiellement - l'objet de formalisation et de transmission, renouvelant ou enrichissant la culture technique du domaine.

Nos résultats accréditent l'hypothèse que, sans véritablement contribuer à « révolutionner» (Havard et al., 2018) la culture technique de la voile sportive, le développement de la navigation sur des voiliers volants est de nature à contribuer au développement de cette culture technique, en accordant une importance accrue à certains aspects de cette pratique, jusqu'à présent peu formalisés dans la littérature technique. Cette contribution de l'apparition de nouveaux supports à la transformation de la culture technique d'un groupe d'utilisateurs plus large a été présentée par Bethwaite (2012), qui constatait que les techniques développées par les utilisateurs de Patikis en Nouvelle-Zélande étaient en fait efficaces sur tous types de bateaux. Si le développement de ces techniques était associé à l'utilisation de bateaux de plus en plus rapides, l'appropriation de ces techniques bénéficiait à l'ensemble des navigateurs. Dans le domaine de la voile volante, trois aspects deviennent plus saillants dans l'expérience des pratiquants. Le premier concerne une appréhension étendue et hybride du "bateau », intégrant de façon systémique des composantes matérielles et des composantes humaines, dans des relations de sensibilité mutuelle, et dans une "tension" coopérative / compétitive permanente. Le deuxième concerne une autonomie relative du bateau en tant que système mécanique, dont la vitesse contribue à façonner un environnement physique (aérologique et hydrologique) propre, ce qui lui confère une certaine « agentivité » du point de vue de l'expérience des pratiquants. Le troisième concerne la prégnance des dimensions émotionnelles dans les expériencestypes associées à la stabilité de vol et aux conditions de son contrôle, portant l'empreinte d'une gestion permanente du risque de perte de contrôle du vol (ex. décrochage des foils), laquelle présente des dangers objectifs pour l'intégrité physique des équipiers et du voilier.

Nous avons visé à travers cette étude à appréhender l'émergence d'une culture technique d'un groupe de "pionniers » d'une pratique en nous inscrivant dans le programme de recherche du cours d'action, rattaché à une approche enactive. Nous avons pour cela construit nos données en élaborant un format d'entretiens visant l'expression de la culture propre des participants. À travers notre analyse de données, nous avons cherché à mettre en évidence les dimensions partagées de la culture propre des participants, par l'identification d'expériences types, puis la comparaison de réseaux construits à partir des principes d'interprétation. Nous avons ainsi pu repérer l'émergence d'une culture technique "locale » (Theureau, 2015) au sein du groupe des participants à l'étude. Les principales limites de cette étude reposent sur: (a) une 
focalisation a priori sur la notion de stabilité de vol, cette focalisation présentant toutefois l'avantage de circonscrire le contenu des entretiens, et se justifiant par la connaissance préalable des auteurs du caractère central de cette notion dans la navigation sur foils, et (b) une description «statique» d'un état de connaissances correspondant au moment des entretiens, ne rendant pas compte de l'évolution dynamique de la culture technique propre à chaque individu, ni des relations entre celle-ci, la culture du groupe étudié et la culture plus large du domaine de la voile sportive.

Cette relation entre différents niveaux de culture peut néanmoins être envisagée d'un point de vue théorique. En premier lieu, nous pouvons spéculer que la culture technique du groupe de participants que nous avons étudié correspond à une culture locale (Theureau, 2015) émergente dans la communauté restreinte des pratiquants et des praticiens de la voile volante. En deuxième lieu, la formalisation de cette culture émergente, à laquelle participe potentiellement cet article, et la diffusion de ces résultats sous des formes vulgarisées auprès d'athlètes, entraineurs et formateurs, participe à son intégration à une culture globale (Theureau, 2015) d'une communauté plus vaste d'acteurs de la voile sportive ou de la voile en général. À ce titre il pourra être intéressant d'analyser au cours des prochaines années, l'évolution conjointe de telles formalisations, et leur appropriation dans l'activité et dans les discours des pratiquants.

\section{BIBLIOGRAPHIE}

Alter N. (2000). L'innovation ordinaire. Paris : PUF.

Bethwaite, F. (2012). Fast Handling Technique. London : Adlard Coles Nautical.

Chéret, B. (2006). Voile légère techniques et sensations. Paris : FFV. (Coll. Voile Gallimard)

Clark, D. J., Ellsworth, W. M., \& Meyer, J. R. (2004). The Quest for Speed at Sea. Technical digest, April 2004. Carderock: Naval Surface Warfare Center, Carderock division

Dant, T., \& Wheaton, B. (2007). Windsurfing: An extreme form of material and embodied interaction? Anthropology today, 23(6), 8-12.

Defrance, J. (1985). L'adoption de la perche en fibre de verre. Culture technique, 13, 257-268.

Destuynder, P., \& Fabre, C. (2018). On the Stability of Racing Sailing Boats with Foils. Chinese Annals of Mathematics, Series B, 39, 427-450.

Dosi, G. (1982). Technological Paradigms and Technological Trajectories: A Suggested Interpretation of the Determinant and Direction of Technological Change. Research Policy, 11(3), 147-162.

Février, C., \& Monsonnec, F. (2011). On a marché sur la mer. Voiles et Voiliers, 484, 19-21.

Flageul, E. (2018). Travaux de fin d'année du Foiling Workshop! https://foilenvsn.wordpress.com/ 2018/11/09/travaux-de-fin-dannee-du-foiling-workshop/ 
Flichy, P. (2003). Le temps de la technique. In P. Flichy (Ed.), L'innovation technique : Récents développements en sciences sociales. Vers une nouvelle théorie de l'innovation (pp. 145-178). Paris : La Découverte.

Freeman, C., \& Perez, C., (1988). Structural crisis of adjustment, business cycles and investment behaviour. In G. Dosi, C. Freeman, R. Nelson, G. Silverberg, \& L. Soete (Eds.), Technical Change and Economic Theory (pp. 38-66). London : Pinter.

Gouard, P. (1988). Voile : Nouvelles techniques pour gagner. Paris : Chiron.

Havard, G., Seray, T., \& Verneuil, T. (2018). La révolution du foil : De la plage au large, comment le foil change la pratique de la mer. Présenté à Foil Racing Conférence, Vannes, France.

Julien, M-P., \& Rosselin, C. (2005). Culture matérielle incorporée et processus d'identification. Navigateurs de compétition et croisiéristes « bord à bord ». In S. Tabois (Ed.), Corps en société (pp. 75-91). Poitiers : Maison de l'homme et de la société.

Lacombe, P. (2002). La planche à voile. Techniques \& Culture. Revue semestrielle d'anthropologie des techniques, 39, 1-18.

Leroi-Gourhan, A. (1964). Le geste et la parole. Paris : Albin Michel.

Malafouris, L. (2019). Mind and material engagement. Phenomenology and the Cognitive Sciences, 18(1), 1-17.

Maturana, H. R., \& Varela, F. J. (1987). The tree of knowledge: The biological roots of human understanding. Boston : Shambhala.

Püschl, W. (2018). High-speed sailing. European Journal of Physics. 39(4). https://iopscience.iop.org/ article/10.1088/1361-6404/aab982

Rosch, E. (1978). Principles of categorization. In E. Rosch, \& B.B. Lloyds (Eds.), Cognition and Categorization (pp. 27-48). Hillsdale : Lawrence Eribaum Associates.

Saury, J. (1990). Technique Planche : Quelle démarche pour déterminer la « référence » technique à atteindre? Les cahiers de l'E.N.V., 7, 21-30.

Strauss, A., \& Corbin, J. (1990). Basics of qualitative research: grounded theory procedures and techniques. London : Sage.

Terret, C., Robène, L., \& Grosjean, B. (2017). Histoire des techniques en canoë-kayak freestyle. Movement \& Sport Sciences - Science \& Motricité, 97(3), 53-64.

Theureau, J. (2004). Le cours d'action: Méthode élémentaire. Toulouse : Octarès.

Theureau, J. (2006). Le cours d'action: Méthode développée. Toulouse : Octarès.

Theureau, J. (2015). Le cours d'action : l'enaction \& l'expérience. Toulouse : Octarès.

Varela, F. J. (1989). Autonomie et connaissance: Essai sur le vivant. Paris : Seuil.

Vermersch, P. (1994). L'Entretien d'explicitation. Paris : ESF.

Vigarello, G. (1988). Techniques d'hier... Et d'aujourd'hui : Une histoire culturelle du sport. Paris : Robert Laffont.

Warnier, J.-P. (1999). Construire la culture matérielle : L'homme qui pensait avec ses doigts. Paris : PUF. 


\section{NOTES}

1. Nous entendons ici les notions d'invention et innovation au sens de Alter (2000), en considérant l'invention comme l'apport d'une solution nouvelle à un problème abstrait, indépendamment de son contexte économique et social, et l'innovation comme le processus par lequel une communauté s'empare de cette invention. De ce point de vue, l'invention et l'innovation n'obéissent pas à la même temporalité : l'invention est un événement circonscrit dans le temps alors que le processus de l'innovation peut s'étendre dans le temps.

2. La barre sert à diriger le voilier, les écoutes sont les cordages permettant à l'équipage de modifier l'angle d'une voile par rapport à l'axe longitudinal du voilier.

3. Par culture technique nous entendons ici en première approche un ensemble de connaissances relatives à un domaine technique particulier (ex. une pratique sportive), qui sont partagées au sein d'un groupe délimité de pratiquants ou de praticiens, et qui rendent compte d'usages, d'interprétations et/ou de solutions opératives communes au sein de ce groupe. Nous précisons plus loin cette définition dans la perspective théorique dans laquelle nous nous inscrivons.

4. Border une voile est une action consistant à tirer sur une écoute de voile pour réduire l'angle entre la voile et l'axe longitudinal du bateau. À l'inverse choquer une voile consiste en l'action de relâcher une écoute pour augmenter cet angle.

5. Au moment de la publication de l'ouvrage de Chéret (2006), Philippe Presti incluait déjà dans son palmarès deux titres de champion du monde de Finn, deux sélections olympiques (en Finn et en Soling) et une $5^{\mathrm{e}}$ place aux championnats du monde de Star.

6. Le Laser est un dériveur solitaire faisant partie des séries olympiques, et notoirement considéré comme voilier "lent» en comparaison des autres voiliers constituant les séries olympiques.

\section{RÉSUMÉS}

Les innovations technologiques participent aux évolutions de la culture technique des disciplines sportives. Le domaine de la voile sportive offre actuellement une opportunité pour étudier le développement d'une culture technique liée à la diffusion d'une innovation matérielle: les «foils», permettant aux voiliers de voler au-dessus de l'eau. La présente étude visait à : (a) appréhender la nature et la structure des connaissances de pratiquants et praticiens pionniers de la navigation volante, en relation avec la question de la gestion et du contrôle de la stabilité de vol, et (b) à appréhender le développement d'une culture technique propre à la navigation volante. Nous avons réalisé des entretiens de partage d'expérience avec douze participants reconnus pour leur implication dans la pratique ou l'encadrement de la voile volante. L'analyse a consisté en l'identification d'expériences types associées à la reconnaissance et au contrôle de la stabilité de vol, ainsi qu'à la catégorisation et la mise en réseau d'éléments explicatifs d'états de stabilité du vol, du point de vue des connaissances des participants. Ces deux versants de l'analyse ont permis d'appréhender l'émergence d'une culture partagée au sein du groupe de participants. Nos résultats permettent de suggérer un développement de la culture technique de la voile volante comme intégrant une forte dimension émotionnelle, et mettant en avant l'incorporation de l'équipage à un bateau présentant les caractéristiques d'un système autonome. 
Technological innovations contribute to developments in the technical culture of sports. The current field of competitive sailing provides an opportunity to study the development of a technical culture linked to the spread of an innovation in equipment - that of "hydrofoils", which allow sailboats to "fly" over the water. The objectives of this study were to investigate: (i) the nature and structure of the knowledge of "pioneering" hydrofoil sailors, in relation to the question of flight stability management and control, and (ii) the development of a technical culture specific to hydrofoil sailing. We conducted "experience sharing" interviews with 12 participants recognized for their involvement in the practice or teaching of hydrofoil sailing. The analysis consisted in identifying typical experiences related to flight stability recognition and control, and in the categorization and inter-linking of explanatory elements on flight stability states, from the point of view of the participants' knowledge. These two sides of the analysis helped to apprehend the emergence of a shared culture within the group of participants. Our results suggest the development of a technical culture of hydrofoil sailing that integrates to a greater extent the emotional dimension of this practice, and highlight the crew's incorporation into a boat that presents the characteristics of an autonomous system.

\section{INDEX}

Mots-clés : sport, voile, hydrofoils, culture technique, cours d'action

Keywords : sport, sailing, hydrofoils, technical culture, course of action

\section{AUTEURS}

\section{ÉRIC TERRIEN}

Nantes Université, Movement - Interactions - Performance, MIP, EA 4334, F-44000 Nantes eric.terrien@univ-nantes.fr

\section{BENOÎT HUET}

Nantes Université, Movement - Interactions - Performance, MIP, EA 4334, F-44000 Nantes benoit.huet@univ-nantes.fr

\section{JACQUES SAURY}

Nantes Université, Movement - Interactions - Performance, MIP, EA 4334, F-44000 Nantes

jacques.saury@univ-nantes.fr 